\title{
Sportomics analysis of a high-intensity functional training method, the CrossFit
}

\section{Análisis sportómico de un método de entrenamiento funcional de alta intensidad, el CrossFit}

Luis C. O. Gonçalves

Mestre em Ciência da Motricidade Humana - Universidade Castelo Branco (UCB), Rio de Janeiro, Brasil; Doutorando em Ciências da Saúde - Universidade Federal de Mato Grosso (UFMT). Faculdade de medicina, Cuiabá, Brasil Instituição: Universidade Federal do Estado do Rio de Janeiro (UNIRIO), Laboratório de Bioquímica de Proteínas

Endereço: Av. Pasteur, 296 - Urca. 22290-240 - Rio de Janeiro, RJ - Brasil

E-mail: luisogoncalves@yahoo.com.br

\section{Douglas D. C. Santiago}

Mestre em Ciências da Saúde - Universidade Federal de Mato Grosso (UFMT). Faculdade de medicina, Cuiabá, MT - Brasil.

Instituição: UFMT - Departamento de Química - Instituto de Ciências Exatas e da Terra

Endereço: Av. Fernando Correa, 2367. Boa Esperança. 78060900 - Cuiabá, MT - Brasil

E-mail: douglasdaniel.santiago@gmail.com

Anibal M. M. Neto

Doutor em Genética e Bioquímica - Universidade Federal de Uberlândia (UFU). Uberlândia, MG - Brasil

Instituição: UFMT - Instituto de Ciências Biológicas e da Saúde.

Endereço: Rodovia MT 100, Km 3,5 s/n. Centro. 78696000 - Pontal do Araguaia, MT - Brasil

professoranibal@yahoo.com.br

\section{Hugo da Silva Paulino Ferreira}

Licenciado em Educação Física - Centro Universitário do Rio de Janeiro (UNIRJ). Rio de Janeiro, Brasil

Instituição: Universidade Federal do Estado do Rio de Janeiro (UNIRIO), Laboratório de Bioquímica de Proteínas.

Endereço: Av. Pasteur, 296 - Urca. 22290-240 - Rio de Janeiro, RJ - Brasil E-mail: hugodasilvap@live.com

Marcio V. A. Verli

Mestre em Ciências da Saúde - Universidade Federal de Mato Grosso (UFMT). Faculdade de medicina, Cuiabá, MT - Brasil

Instituição: UFMT - Departamento de Química - Instituto de Ciências Exatas e da Terra 
Endereço: Av. Fernando Correa, 2367. Boa Esperança. 78060900 - Cuiabá, MT - Brasil

E-mail: marcioaverli@gmail.com

\section{Renan Muniz-Santos}

Graduando em Medicina - Universidade Federal do Estado do Rio de Janeiro (UNIRIO). Rio de Janeiro, Brasil

Instituição: Universidade Federal do Estado do Rio de Janeiro (UNIRIO), Laboratório de Bioquímica de Proteínas

Endereço: Av. Pasteur, 296 - Urca. 22290-240 - Rio de Janeiro, RJ - Brasil

E-mail: renanmuniz@edu.unirio.br

\section{Jaqueline Santos Silva Lopes}

Doutora em Ciências da Saúde - Universidade Federal de Mato Grosso (UFMT). Faculdade de medicina, Cuiabá, Brasil

Instituição: UFMT - Departamento de Química - Instituto de Ciências Exatas e da Terra

Endereço: Av. Fernando Correa, 2367. Boa Esperança. 78060900 - Cuiabá, MT - Brasil

E-mail: jaqueee-santosss@hotmail.com

Claudia M. B. Andrade

Doutora em Ciências Biológicas - Universidade Federal do Rio Grande do Sul (UFRGS), RS, Brasil

Instituição: UFMT - Departamento de Química - Instituto de Ciências Exatas e da Terra

Endereço: Av. Fernando Correa, 2367. Boa Esperança. 78060900 - Cuiabá, MT - Brasil

E-mail: claudia.mb.andrade@gmail.com

\section{ABSTRACT}

To identify the acute hematological and biochemical changes induced by a Crossfit ${ }^{\mathrm{TM}}$ class, ten men were divided into CF group $(\mathrm{N}=5)$ and control group $(\mathrm{N}=5)$. Blood and urine were collected: pre-exercise (T1), after exercise (T2), and 12 post-exercise (T3). Blood cells, urea, cortisol, lactate, creatine Kinase (CK), and microalbuminuria (MAU) had measured. There was a record of handgrip strength (HGS), heart rate (HR), and systolic blood pressure (SBP), with the calculation of the double product (DP). MAU showed an increase in the order of $14,000 \%$, with a return to normal (T3). The DP increased $83 \%$ in response to exercise, and this increase seems to be due to HR, which increased $76 \%$. Cortisol and lactate showed an acute increase induced by the method, $47 \%$ for cortisol and $874 \%$ for lactate, respectively, with recovery less than 12 hours. The correlations between the study variables represent a future perspective for studies in sports medicine. The acute excretion of proteins by the kidneys in an acute way, already in the first exercise session, can in the long-term cause damage to this organ. MAU presented itself as more indicated than urea, the most usual renal marker. 
Keywords: Sportomics, Exercise metabolism, Stress Biomarkers, Damage degree.

\section{RESUMEN}

Para identificar los cambios hematológicos y bioquímicos agudos inducidos por una clase de Crossfit ${ }^{\mathrm{TM}}$, se dividió a diez hombres en el grupo de CF $(\mathrm{N}=5)$ y el grupo de control $(N=5)$. Se recogió sangre y orina: antes del ejercicio (T1), después del ejercicio (T2) y 12 después del ejercicio (T3). Se midieron las células sanguíneas, la urea, el cortisol, el lactato, la creatina quinasa (CK) y la microalbuminuria (MAU). Se registró la fuerza de prensión de la mano (HGS), la frecuencia cardíaca (FC) y la presión arterial sistólica (PAS), con el cálculo del doble producto (DP). La MAU mostró un aumento del orden del $14.000 \%$, con un retorno a la normalidad (T3). EI DP aumentó un 83\% en respuesta al ejercicio, y este aumento parece deberse a la FC, que aumentó un $76 \%$. El cortisol y el lactato mostraron un aumento agudo inducido por el método, 47\% para el cortisol y $874 \%$ para el lactato, respectivamente, con una recuperación inferior a 12 horas. Las correlaciones entre las variables del estudio representan una perspectiva de futuro para los estudios en medicina deportiva. La excreción aguda de proteínas por los riñones de forma aguda, ya en la primera sesión de ejercicio, puede a largo plazo causar daños en este órgano. El MAU se presentó como más indicado que la urea, el marcador renal más habitual.

Palabras clave: Sportómica, Metabolismo del ejercicio, Biomarcadores de estrés, Grado de daño.

\section{HIGHLIGHTS}

- The calculation of the double product proved to be an excellent non-invasive predictor of stress level.

- Microalbuminuria should be the marker of choice for monitoring the impact on kidney function caused by exercise, as it is more acute than classic blood markers.

- In the case of changes in the hematocrit between collection times, this indicates changes in blood concentration, requiring the application of the correction factor in all blood biomarkers.

- The present study presents the correlation between the main biomarkers, cells, and physiological variables induced by the training method in a heat map, indicating the positive and negative correlations between these data.

- Knowing baseline values and common acute changes in cellular and acellular components of body fluids, physicians and sports professionals can assess whether the degree of stress and recovery time at baseline levels of their athletes and practitioners is compatible with expectations, where a deviation in an individual, it will indicate the need for prior attention, avoiding problems such as rhabdomyolysis, renal damage, and immunosuppression due to overtraining. 


\section{INTRODUCTION}

The use of Biomarkers in clinical trials has increased over the years, seeking to assess potential risk factors, incidence, and degree of disease [1].

CF, a submodality of HIFT (High-Intensity Functional training), has been conquering more and more practitioners worldwide, characterized by its functional and dynamic structure where the exercises can be performed with short movements and at high speed [2]. The literature suggests more significant attention to Extreme Conditioning Programs, another classification given to the CF. A study that used Men and Women and had HIIT as a study tool had its results expressed in decreased circulating lymphocytes and reduced exerciseinduced immunity [3].

In this case, the importance of studies that analyze Biomarkers in different situations is evident. A study that evaluated the apoptotic behavior of lymphocytes in an incremental stress test showing that the more strenuous the exercise, the higher the percentage of cell apoptosis. Apoptotic levels returned to normal after 40 to 60 minutes after exercise [4].

Some studies show that CF causes as much injury as other modalities ${ }^{5}$ the same studies only associates biomechanical injuries. Therefore, and also evaluating the importance of analyzing biomarkers, this study aimed to assess the behavior of biochemical markers before, shortly after, and 12 hours after the CF session.

The gap left by science supports the need for sportomics studies on the HIIT method [6]. The main objective of the present work was to identify the acute hematological and biochemical changes induced by a HIFT or Crossfit class in competing practitioners concerning the control group.

\section{MATERIALS \& METHODS}

Ten subjects, male, aged 27 to 40 years, volunteered for the experiment and were separated into two groups, the CF group $(N=5)$, where they should have a minimum experience of 6 months of $\mathrm{CF}$, and the control group $(\mathrm{N}=5)$. 
The investigation met the requirement for research on human beings (National Health Council, 2012) approved by the Ethics and Research Committee, number 2,230,073 of the Federal University of Mato Grosso (UFMT), registered at clinicaltrials.gov (NCT 03522883). All volunteers gave written consent after being informed about the nature and procedures of the study.

This is an observational and cross-sectional cohort study, widely used in epidemiological assessments, from the subgroup of studies in special populations. This type of study, in a previously defined population, measures exposure and its effects.

In the case of the present study, we sought to assess metabolic stress and chronic and acute impacts on the health of a particular population, in this case of practitioners of $\mathrm{CF}$.

For the comparison of data between different times, as the variance of the biomarkers of choice is unknown for this population, the indicated would be to apply comparison tests of paired groups, with the adoption of the significance level of $5 \%, P \leq 0.05$. First, a test should be adopted to verify the normal distribution of data by the Shapiro-Wilk test, which may result in two possibilities:

1 - value extracted from $p \leq 0.05$, the Mann-Whitney non-parametric test is applied.

2 - value extracted from $p>0.05$, a typical first apply the Equal Variance Test if Equal Variance Test Failed $(p \leq 0,05)$ will be applied Mann-Whitney Test, but if Equal Variance Test passed $(p>0,05)$ paired T-test has applied.

To create supplementary figure 4 , first, we apply the Spearman test between all data, so we make a heat map with results. The values ranged from deep red to 1 to deep blue to -1 , passing through white at zero in this heat map.

It was used the symbols of \# for different from pre-time, * different from control to the same time, and $\S$ different from the previous time.

To measure the mass, a digital scale (Aqua plenum® with a capacity of $180 \mathrm{~kg}$ and a graduation of 100 grams has used. 2.1 meters). An Omron® blood pressure device model HEN 6124 has been used, and heart rate has been measured with a Polar® RS 800 CX digital device. 
The double product has calculated by multiplying heart rate by systolic blood pressure for the same time.

The Handgrip Strength has obtained with a Jamar® handgrip dynamometer, with a $0.5 \mathrm{Kg}$ graduation and a maximum capacity of $100 \mathrm{KgF}$.

Blood and urine had collected from the participants at times: pre-exercise (T1), immediately after exercise (T2), and 12 post-exercise (T3). The analysis of these fluids for erythrocyte, hematocrit, hemoglobin, eosinophils, neutrophils, lymphocytes, monocytes was performed manually with optical microscopes, micro and macro hematocrit centrifuges, manual hematological counters, capillary tubes, matte slides, and panoptic dye.

Urea was measure by an enzymatic colorimetric method with the Bioclin K047 kit, cortisol by chemiluminescence, lactate with the Labtest 138 enzyme kit, CK enzyme with the Labtest 117 kinetic kit, and microalbuminuria with immunoturbidimetry, all in triplicate and following the manufacturers' recommendations contained in the kits mentioned above.

The CF group performed the Workout Of the Day (WOD), which consisted of Warm-up (20m on a cycle ergometer, 20 strokes on the Rowing and 100 Double Unders) movement and strength work (50 Thruster and 50 Wall Ball) and the WOD (25 Sit Up, 50 Air Squat, 25 Box Jump Over, 50 Burpees Over the Bar and 25 Handstand Push Up) lasting 50 minutes. The control group did not perform any exercises.

\section{RESULTS}

Supplementary Table 1 presented the anthropometric characteristics of the participants $(n=10)$, with age $(34.7 \pm 6.94)$ years, body mass $(90.1 \pm 17.89)$ kilograms, height (1.78 \pm 0.10$)$ meters, and body mass index (28.38 \pm 3.82$)$.

The hydration status of the participants was constant during the pre-and post-exercise times (Supplementary Figure 1), showing that the values presented for all biomarkers were changed by the training method and not by hemodilution or hemoconcentration. 
Microalbuminuria showed an increase in the order of $14,000 \%$ induced by the method, with a return to normal values 12 hours after the end of the exercise (Figure 1).

Regarding the cardiovascular component, the double product increased $83 \%$ in response to exercise, and this increase seems to be due to heart rate, which increased $76 \%$ (Figure 2B). Systolic blood pressure had a slight increase of $3 \%$ (Figure $2 \mathrm{~A}$ ).

Only monocytes and erythrocytes showed alteration in the cellular component of blood, decreasing between time immediately after exercise and 12 hours after the end (Supplementary Figure 2).

In addition to being stress markers and stress intensity, cortisol and lactate are important immunomodulators, showed an acute increase induced by the method, being $47 \%$ for cortisol and $874 \%$ for lactate. Both with recovery less than 12 hours (Figure 3 ).

Other components without alteration of the cellular and acellular portions of the blood, in addition to the Hand Grip Strength, were shown (Supplementary Table 2).

figure 4 presented the correlations between the parameters measured for the control group (A) and the CF group (B). Colors ranged from deep blue for values closer to -1 (negative correlation) to white to zero, then shades of red for positive values and intense red for values closer to 1 .

\section{DISCUSSION}

In recent years, researchers have sought to understand the metabolic alterations associated with immune responses, called immunometabolism. As oxygen is central to all metabolism, hypoxia is recognized for contributing to inflammatory and immunological responses. Inflammatory hypoxia emanates from a combination of recruited inflammatory cells, including neutrophils, eosinophils, and monocytes, high rates of oxidative metabolism, and the activation of multiple enzymes during inflammation [7]. 
In addition to studies on immunometabolism, research on a modern syndrome has appeared in recent decades, rhabdomyolysis, which corresponds to the breakdown of muscle tissue, resulting in the release of intracellular constituents in extracellular fluid and circulation, responsible for triggering complications associated with acute kidney injury. Some factors increase the risk of rhabdomyolysis, such as exercise, dehydration, anabolic steroids, medications, and illicit drugs, such as cocaine and cannabinoids, viral diseases such as dengue or Influenza A., the use of electrostimulation, and saunas. In this scenario, the serum dosage of $\mathrm{CK}$ seems to be the most widely used clinical marker to verify muscle damage [8].

In the hypothesis of rhabdomyolysis induced by the training method, a biomarker appears to join $\mathrm{CK}$ as an efficient biomarker, increasing when this syndrome has developed from the practice of exercises [9].

Another biomarker of scientific interest over time, cortisol, was carefully observed. The levels of cortisol shown in figure 3 revealed a significant elevation at the moment immediately after exercise, being compatible with the behavior found for CF at the exact moments [10] and which, together with without changes in lymphocytes, demonstrate the level of training of the participants, since our group has previously revealed that the number of immune cells alters according to the intensity of stress [11]. This can be confirmed by the significant increase in lactate (Figure 3) immediately after exercise and recovered at the next moment, showing the high intensity of the training method session [12].

Traditionally, serum lactate has been consistently dosed to measure exercise intensity and fatigue [13] or tissue hypoxia [14]. However, recently this biomarker has been associated with the functioning of the immune system, which may have a local immunosuppressive effect in cases of sepsis [14], and as a signaling molecule that plays essential roles in the regulation of metabolic pathways, in the immune response, in cell-to-cell communication in the tumor microenvironment, and in the behavior of malignant and non-malignant cells, which can affect multiple biological processes during tumor progression [15]. 
Lactate functions as a signaling molecule, serving as a receptor agonist coupled to the G GPR81 protein, involving autocrine and paracrine mechanisms. In the autocrine pathway, lactate has generated by cancer cells and activates GPR81 in cancer cells; in the paracrine pathway, the lactate generated by cancer cells activates GPR81 in the immune cells, endothelial cells, and adipocytes present in the tumor stroma. The result of GPR81 activation promotes angiogenesis, immune evasion, and chemoresistance [16].

In the case of viral diseases, much research has been done in the last decade on developing vaccines with lactate microparticles to modulate cytokines, recruit immune cells, and activate antigen-presenting cells [17]. Recent findings have brought the study of this biomarker to the fore again in the last decade and aroused interest in several fields of health.

The current study demonstrated that at the collection moment when lactate increased (post), there was a decrease in the levels of neutrophils, which can confirm the acute immunomodulation by lactate.

Another biomarker that acts as an immunomodulatory is cortisol, which has an immunosuppressive effect and influences the immune function of the liver, modulating the synthesis of mRNAs, GR (glucocorticoid receptor), SOCS-1 (cytokine-I signal suppressor), and IGF-1, in addition to the amount and activity of hepcidin [18]. Despite the interest in the influence of cortisol on the modulation of the immune system, which has lasted for decades [19], it remains a current issue and is closely followed by researchers [20].

In the current study, serum cortisol levels showed a growth post-exercise time, with behavior similar to the levels of lactate, microalbuminuria, heart rate, and double product, but with antagonistic behavior neutrophils.

Eosinophils are primitive myeloid cells derived from bone marrow precursors and require the intervention of interleukin (IL-5) for their survival and persistence in blood and tissues [21]. Eosinophils are a minority circulating granulocyte, classically considered to defend the host against parasites and promote allergic reactions. However, several new regulatory functions for these cells have been identified in the past decade [22]. These cells can regulate local 
immune and inflammatory responses, and their accumulation in blood and tissues are associated with various inflammatory and infectious diseases [23].

A decrease in levels may represent the metabolic safety of the training method since the literature has previously shown that chronic inflammatory processes cause an elevation in this type of leukocyte, which in many diseases migrate to the affected area. Its elevation and a cytokine known as interleukin 6 (IL-6) increase the expression and action of a protein called hepcidin, which decreases the uptake of iron and other divalent metals in the intestine, inducing anemia [24]. Furthermore, the decrease in serum iron decreases the speed of energy synthesis by the citric acid cycle and the decrease in the formation of the HEME group, which has been synthesized using intermediates from the same cycle [25].

Eosinophilia could be a promising biomarker of inflammatory processes in stress phenomena, for example, exercise, or pathologies such as the metabolic syndrome that has a pro-inflammatory action, it family being cheaper markers to evaluate since they are quantified using only panoptic dye and an optical microscope when compared to cytokines and hormones that require more expensive methods [26]. In just two consecutive days of Crossfit training, levels of IL-6 significantly increased, but without influencing performance, five, which makes this practice riskier.

Infiltration of eosinophils into the tissue affected by inflammation has previously been identified, with migration to the adipose tissue in the case of metabolic syndrome ${ }^{26}$ and the lung tissue in the case of respiratory diseases [27].

Adipose tissue plays a crucial role in maintaining organic metabolic homeostasis; it has filled with a range of immune cells that coordinate and regulates its function. This audio-immune system is highly dynamic, reflecting the physiological state of the organism [28].

As a science, immunology has reached a level of maturity capable of understanding the complexities of the immune system for the first time, with an awareness of the orchestration of antigens and the pace, magnitude, duration, and character of the response of this system, which is controlled hormones, after 
30 years of research in immunology [29]. However, 11 years after this statement, there is still much to be done for a global understanding of immunometabolism, especially when the muscular system started to be considered an endocrine organ, with a large modulation of the immune response [30].

The correlations shown in Figure 4, being $4 \mathrm{~A}$ between the data for the control group and $4 \mathrm{~B}$ for the $\mathrm{CF}$ group, bring a future perspective for further investigations. For the control group, a maximum correlation (1.0) was found between presystolic blood pressure (SBP PRE) and post cortisol (COR POST), between the same presystolic blood pressure (SBP PRE) and post urea (URE POST), and even more intriguing, between the pre and post times of hematocrit (HT PRE \& HT POST) and the pre and post times of urea (URE PRE \& URE POST) in all possibilities.

For the CF group, a maximum correlation (1.0) has been found between pre hematocrit (HT PRE) and pos microalbuminuria (MAU POST), between pos hemoglobin (HB POST) and (MAU POST), between pre (LEU PRE) and (MAU) leukocytes POST), between post neutrophils (NEU POST) and (BAD POST), and also between post heart rate (HR POST) and pre lactate (LAC PRE), between double pre-product (DP PRE) and pre lactate (LAC PRE, and more intriguing between pre and pos handgrip strength (HGS PRE \& POST) and lactate pre (LAC PRE) and between erythrocyte pre and pos (ERY PRE \& POST) and lactate pos (LAC POST).

\section{CONCLUSIONS}

From the advances in the studies of immunometabolism, where the striated skeletal muscle has been recognized as an endocrine and paracrine organ, mainly modulated by the practice of exercises, the need arises to recognize which types of exercise can positively influence the immune system and which can affect this metabolic balance.

For this, it is necessary to recognize the acute and chronic markers of choice and monitor the stress generated by each sport, not only from the 
biomechanical and anatomical point of view but also from the new field of study known as sports.

Cortisol and lactate are potential acute markers of stress, but it is known that these are not only products of metabolism but control the immune response and metabolism.

The behavior of heart rate and double product, being synergistic to that of cortisol and lactate, present this measure as a non-invasive predictor of metabolic stress.

Another biomarker that had a behavior similar to those mentioned above was microalbuminuria (MAU), demonstrating that this type of exercise studied causes an acute excretion of proteins by the kidneys, already in the first exercise session, and may cause damage to this organ in the long term. MAU presented itself as a more indicated biomarker than urea, the most common renal marker in clinical and sports medicine.

The fact that the hematocrit did not show significant changes increases the robustness of the data, indicating that the present findings were due to an acute modulation of immunometabolism and not by hemoconcentration.

Figure 1. The protocol induced an increase in albuminuria—urinary albumin (HuA).

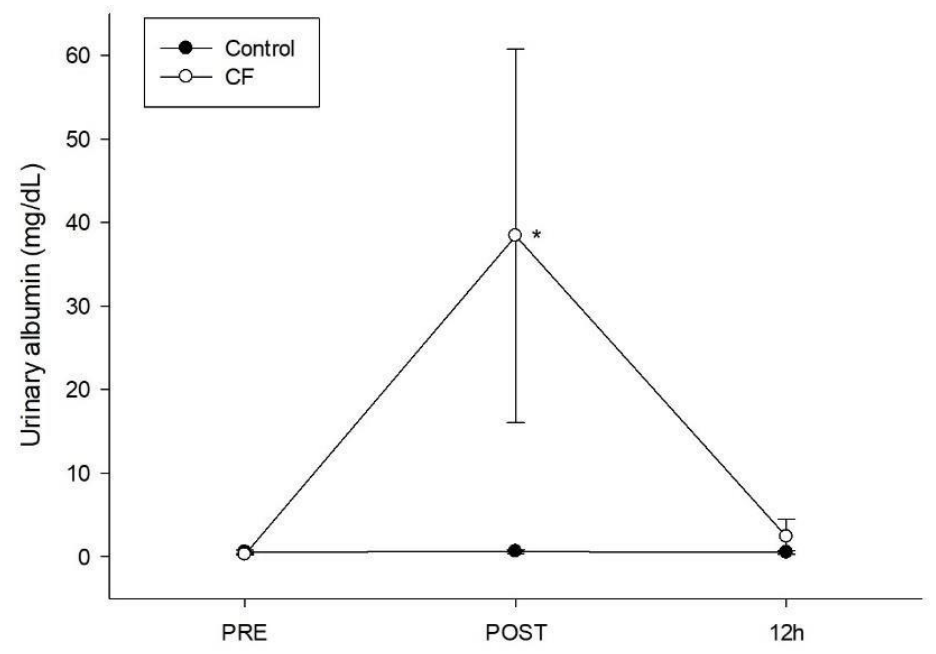




\section{Pid}

Figure 2. Cardiovascular alterations measure by heart rate, systolic blood pressure, and double product.

A

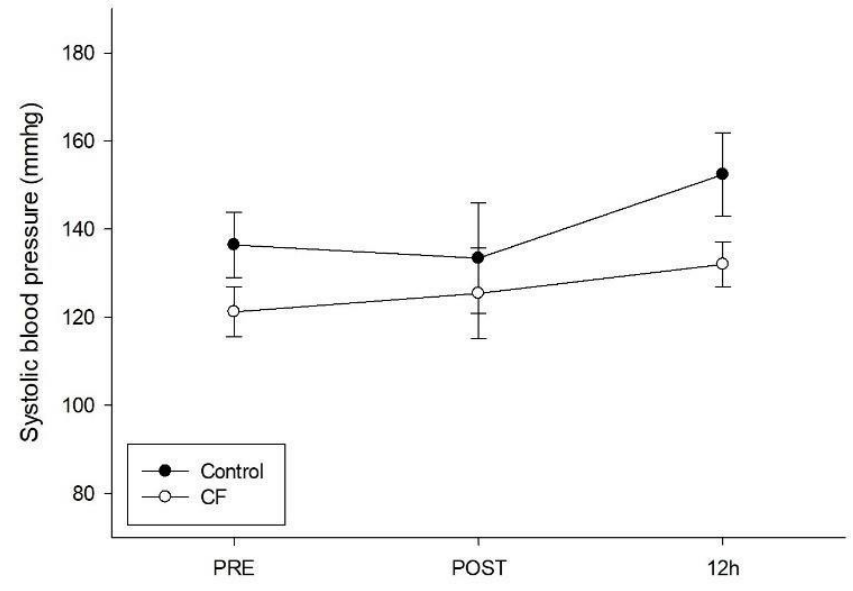

B

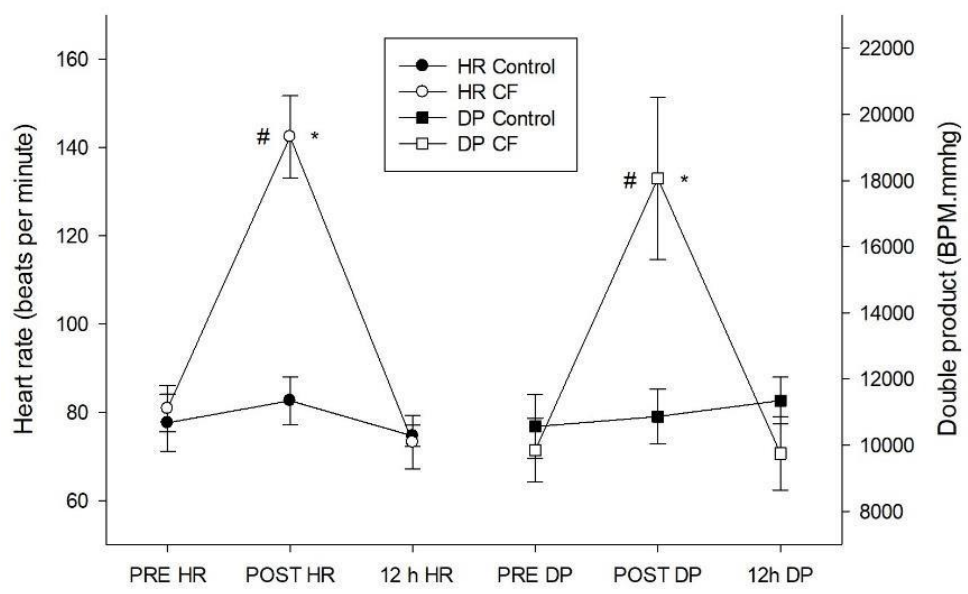

Figure 3. Acute metabolic stress is measured through the concentration of cortisol and lactate.

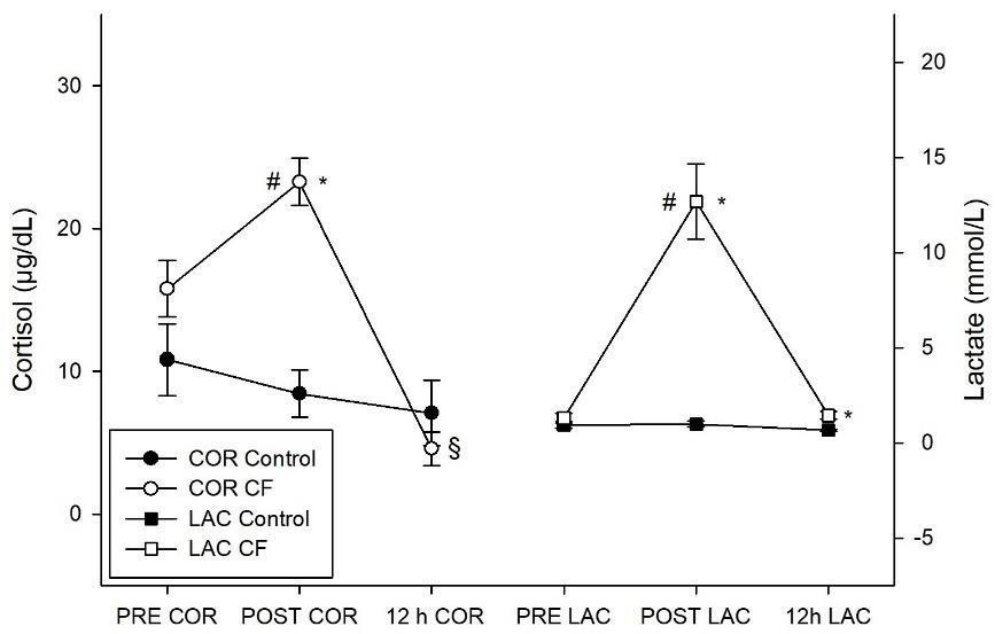

Figure 4. Correlation heat map about biomarkers and other parameters for Control group (A) and CF group (B) 


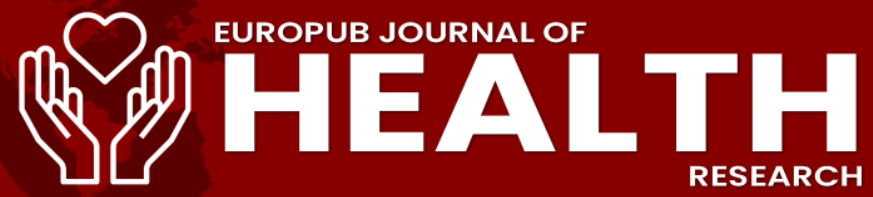

A

Control Group

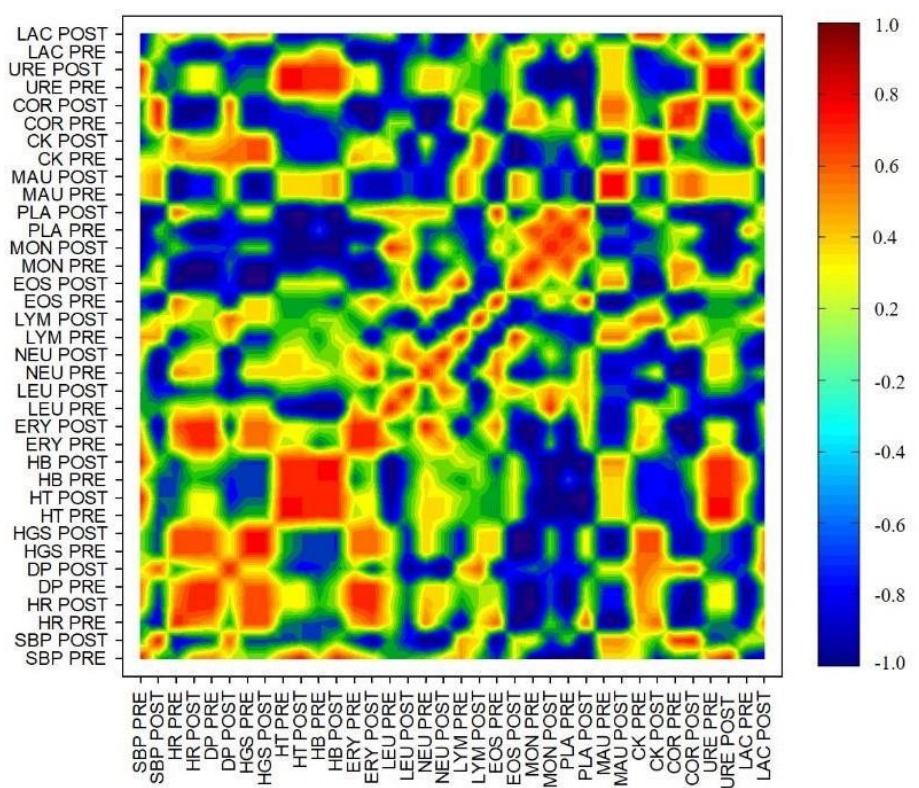

B

CF group

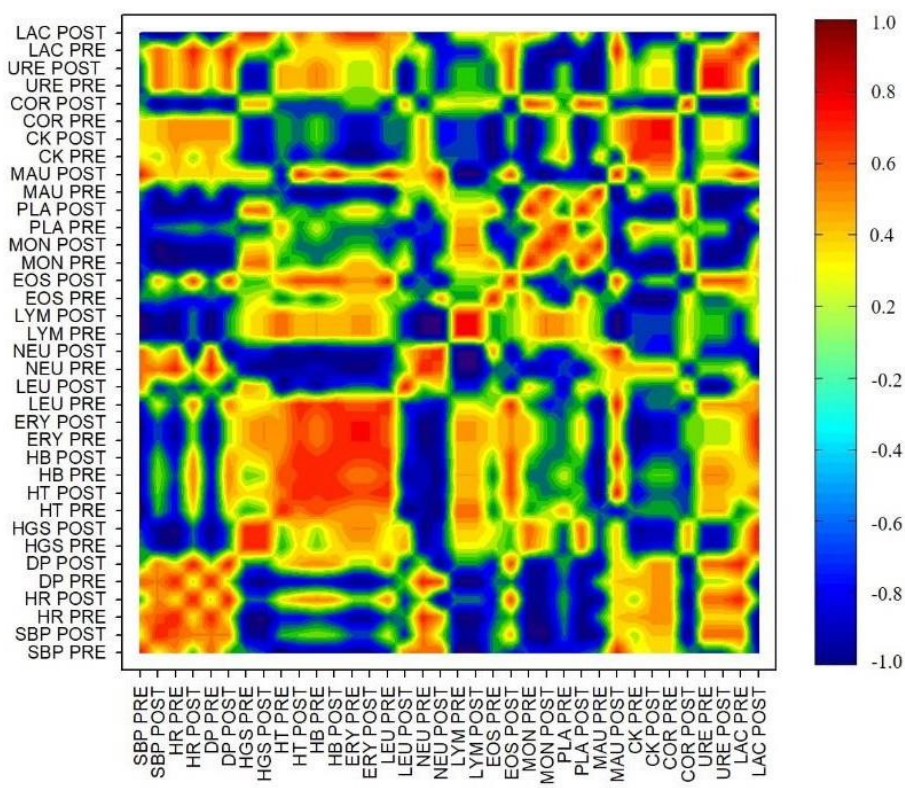

Supplementary Table 1. Subject's characteristics $(n=10)$.

\begin{tabular}{lllllll}
\hline & Mean & Median & SDM & SEM & Min & Max \\
\hline Age $($ years $)$ & 34.7 & 36.0 & 6.94 & 2.20 & 27.0 & 49.0 \\
\hline Mass $(\mathbf{K g})$ & 90.1 & 88.9 & 17.89 & 5.66 & 68.5 & 128.6 \\
\hline Height $(\mathbf{m})$ & 1.8 & 1.8 & 0.10 & 0.03 & 1.6 & 1.9 \\
\hline BMI $\left(\mathbf{K g} / \mathbf{m}^{2}\right)$ & 28.4 & 27.9 & 3.82 & 1.21 & 22.4 & 34.5 \\
\hline
\end{tabular}

BMI - Body Mass Index; SDM - Standard Deviation from the mean; SEM - Standard Error from the mean.

Supplementary Figure 1. Volemia did not change in response to exercise. Hematocrit.

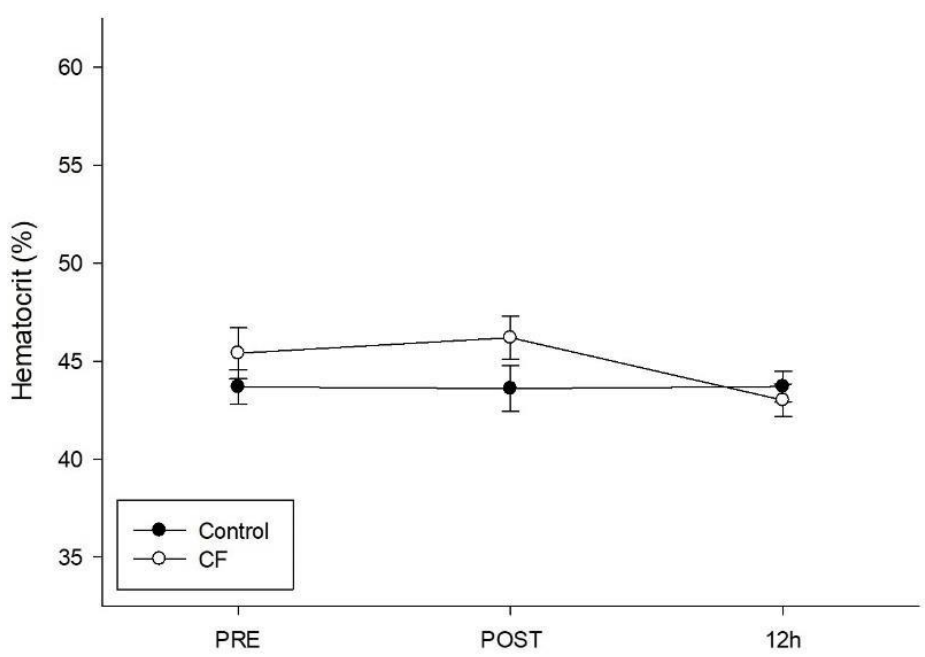

Supplementary Table 2. Other components of the cellular and acellular portions of the blood, in addition to the Hand Grip Strength, did not change during the protocol. 


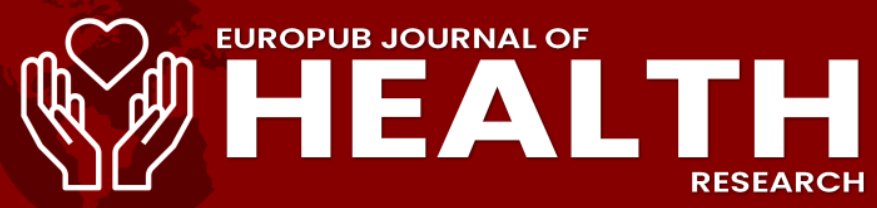

\begin{tabular}{lcccccc}
\hline \multicolumn{1}{c}{ VARIABLES } & \multicolumn{3}{c}{ CONTROL } & \multicolumn{3}{c}{ CROSSFIT } \\
& PRE & POST & $12 \mathrm{~h}$ & PRE & POST & $12 \mathrm{~h}$ \\
\hline Handgrip Strength & $49.7 \pm 6.3$ & $49.0 \pm 6.24$ & $50.4 \pm 6.9$ & $49.0 \pm 3.2$ & $46.4 \pm 4.3$ & $45.6 \pm 3.5$ \\
(Kgf) & 8 & & 1 & 0 & 3 & 4 \\
\hline Hemoglobin (g/dL) & $13.3 \pm 0.3$ & $13.2 \pm 0.35$ & $12.8 \pm 0.3$ & $13.9 \pm 0.4$ & $14.2 \pm 0.4$ & $12.8 \pm 0.3$ \\
& 5 & & 2 & 3 & 7 & 4 \\
\hline Neutrophils (\%) & $58.6 \pm 4.0$ & $60.0 \pm 2.80$ & $59.7 \pm 2.7$ & $56.2 \pm 4.2$ & $43.5 \pm 6.2$ & $58.0 \pm 3.3$ \\
& 8 & & 8 & 1 & 5 & 4 \\
\hline Lymphocytes (\%) & $30.4 \pm 2.3$ & $31.7 \pm 3.50$ & $31.7 \pm 2.4$ & $35.4 \pm 3.1$ & $41.4 \pm 6.3$ & $38.8 \pm 2.9$ \\
& 8 & & 0 & 4 & 2 & 2 \\
\hline Eosinophils (\%) & $1.4 \pm 0.40$ & $2.0 \pm 0.41$ & $0.6 \pm 0.66$ & $0.6 \pm 0.40$ & $1.2 \pm 0.58$ & $0.6 \pm 0.40$ \\
\hline Platelets & $360.2 \pm 26$ & $407.0 \pm 35$. & $354.2 \pm 27$ & $388.6 \pm 20$ & $447.2 \pm 34$ & $404.6 \pm 21$ \\
(thousand/mm ${ }^{3}$ ) & .74 & 74 & .09 & .96 & .67 & .70 \\
\hline Urea (mg/dL) & $45.0 \pm 6.0$ & $44.7 \pm 6.82$ & $46.0 \pm 5.4$ & $38.4 \pm 2.5$ & $40.0 \pm 2.5$ & $43.2 \pm 2.5$ \\
& 7 & & 9 & 6 & 8 & 4 \\
\hline
\end{tabular}

Supplementary Figure 2. Impact on the cellular portion of the blood measured through the differential count of erythrocytes and monocytes.

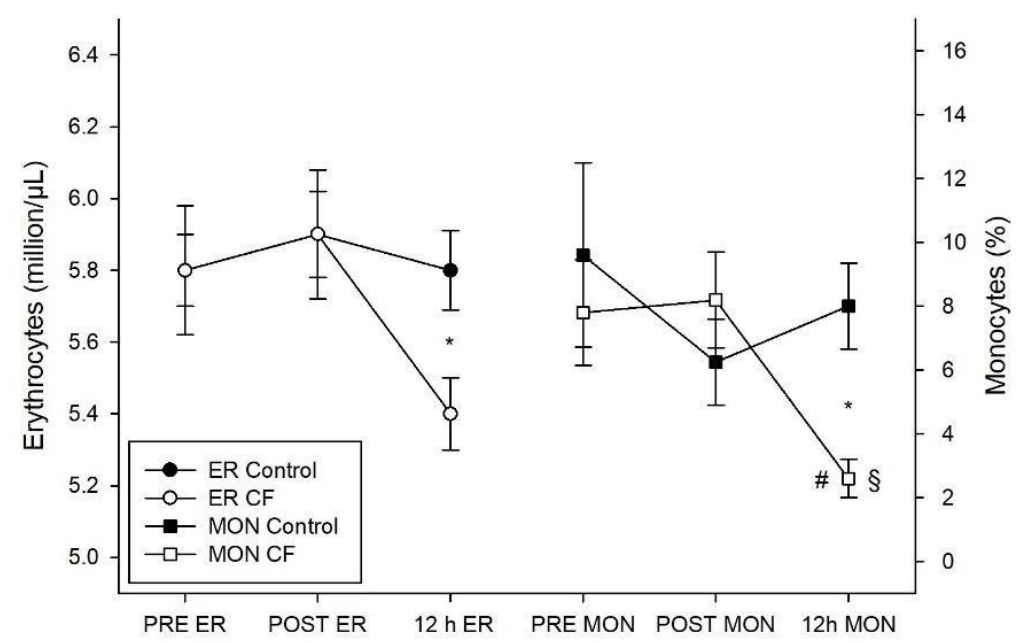


LCOG, AMMN, DDCS, and CMBA conceived and designed the study. LCOG, AMMN, DDCS, HSPF, and MVAV collected the data. LCOG, AMMN, DDCS, RMS, JSSL, and CMBA analyzed the data and wrote the manuscript. All authors read and provided critical feedback on the manuscript before approval.

\section{LIMITATIONS}

The study's main limitation was that evaluating high-level individual sports athletes reduced the sample size concerning population studies, especially in the case of Crossfit, where many high-level teams have a huge coaching staff and only one athlete.

\section{COMPLIANCE WITH ETHICAL STANDARDS}

Ethical approval All procedures performed in studies involving human participants were following the ethical standards of the Leeds Beckett University School of Sport research ethics committee and with the 1964 Helsinki declaration and its later amendments or comparable ethical standards.

\section{CONFLICT OF INTEREST}

The authors declare that they have no conflict of interest.

\section{FUNDING INFORMATION}

The authors made all investments in material, reagents, displacements, and others without a research-funding agency's help. It is a work carried out as a master's thesis in Health Sciences.

\section{ACKNOWLEDGMENT}

We thank the FM fitness-training center for providing the space and the high-level athletes who participated. 


\section{REFERÊNCES}

[1] Strimbu k, Tavel JA. What are biomarkers? Current opinion in HIV and aids 2010; 5(6):463-466 https://doi.org/10.1097/coh.0b013e32833ed177

[2] Tibana RA, de Farias DL, Nascimento DC, da Silva-Grigoletto ME, Prestes J. Relação da força muscular com o desempenho no levantamento olímpico em praticantes de crossfit ${ }^{\circledR}$. Revista Andaluza de Medicina del Deporte 2018; 11(2):84-88 https://doi.org/10.1016/j.ramd.2015.11.005

[3] Mars M, Govender S, Weston A, Naicker V, Chuturgoon A. "High-intensity exercise: a cause of lymphocyte apoptosis?" Biochemical and Biophysical Research Communications 1998; 249(2):366-370 https://doi.org/10.1006/bbrc.1998.9156

[4] Navalta JW, Sedlock DA, Park KS. "Effect of exercise intensity on exerciseinduced lymphocyte apoptosis." International Journal of Sports Medicine 2007; 28(6):539-542 https://doi.org/10.1055/s-2006-955898

[5] Tibana, RA, Almeida LM, Souza NMF, Nascimento DC, Neto IV, Almeida JA, Souza VC, Lopes MF, Nobrega OT, Vieira DC, Navalta JW, Prestes, J. Two consecutive days of crossfit training affects pro and anti-inflamatory cytocines and osteoprotegerin without impairments in muscle power. Front Physiol 2016; 7(260):1-8 https://doi.org/10.3389/fphys.2016.00260

[6] Santiago DDC, Lopes JSS, Neto AMM, Andrade CMB. A systematic review study is analyzing biomarkers in response to high-intensity functional training (HIFT) and high-intensity interval training (HIIT). Archives of Current Research International 2021; 21(3):59-72 https://doi.org/10.9734/acri/2021/v21i330237

[7] Colgan, SP, Futura GT, Taylor CT. Hypoxia and innate immunity: keeping up with the hipsters. Annu Rev Immunol 2020; 38:341-363 https://doi.org/10.1146/annurev-immunol-100819-121537

[8] Gonçalves LCO, Paulino EV, Ferreira LPR, Matta NLC, Silva PL, Lopes JSS, Neto AMM. Rhabdomyolysis: a narrative review of the main causal factors and physiological outcomes. World Journal of Pharmacy and Pharmaceutical Sciences 2020; 9(3):1-11

[9] Meyer M, Sundaram S, Schafhalter-Zoppoth I. Exertional and CrossFitinduced rhabdomyolysis. Clin J Sports Med 2018; 28(6):92-94 https://doi.org/10.1097/jsm.0000000000000480

[10] Mangine GT, Van Dusseldorp TA, Feito Y, Holmes AJ, Serafini PR, Box AG, Gonzalez AM. Testosterone and cortisol responses to five high-intensity 
functional training competition workouts in recreationally active adults. Sports 2018; 6(3):1-14 https://doi.org/10.3390/sports6030062

[11] Gonçalves LCO, Bessa A, Freitas-Dias R, Luzes R, Wernwck-de-Castro JPS, Bassini A, Cameron LC. A sportomics strategy to analyze the ability of arginine to modulate both ammonia and lymphocyte levels in blood after highintensity exercise. J Int Soc Sports Nutr 2012; 9(1):1-9 https://doi.org/10.1186/1550-2783-9-30

[12] Mate-Munoz JL, Lougedo JH, Barba M, Garcia-Fernandez P, GarnachoCastano MV, Dominguez R. Muscular fatigue in response to different modalities of CrossFit sessions. PLOS One 2017; 12(7):2017 https://doi.org/10.1371/ journal.pone. 0181855

[13] Dominguez R, Mate-Munoz JL, Serra-Paya N, Garnacho-Castano MV. Lactate threshold as a measure of aerobic metabolism in resistance exercise. Int J Sports Med 2018; 39(3):163-172 https://doi.org/10.1055/s-0043-122740

[14] Nolt B, Tu F, Wang X, Ha T, Winter R, Willians DL, Li C. Lactate and immunosuppression in sepsis. Shock 2018; 49(2):120-125 https://doi.org/10.1097/shk.0000000000000958

[15] Ippolito L, Morandi A, Giannoni E, Chiarugi P. Lactate: a metabolic driver in the tumor landscape. Trends Biochem Sci 2019; 44(2):153-166 https://doi.org/10.1016/j.tibs.2018.10.011

[16] Brown TP, Ganapathy V. Lactate/gpr81 signaling and próton motive force in câncer: role in angiogenesis, immune escape, nutrition, and Warburg phenomenon. Pharmacol Ther 2019; 206:107451 https://doi.org/10.1016/..pharmthera.2019.107451

[17] Lu T, Hu F, Yue H, Yang T, Ma G. The incorporation of cationic property and immunopotentiator in poly (lactic acid) micropartícules promoted the immune response against chronic hepatitis b. J Control Release 2020; 321:576-588 https://doi.org/10.1016/ j.jconrel.2020.02.039

[18] Shepherd BS, Spear AR, Philip AM, Leaman DW, Stepien CA, SepulvedaVillet OJ, Palmquist DE, Vijayan MM. Effects of cortisol and lipopolysaccharide on the expression of select growth-, stress-, and immune-related genes in rainbow touch liver. Fish Sellfish Immunol 2018; 74:410-418 https://doi.org/10.1016/j.fsi.2018.01.003

[19] Jefferies WM. Cortisol and immunity. Med Hypotheses 1991; 34(3):198-208 https://doi.org/10.1016/0306-9877(91)90212-h 
[20] Baekelandt S, Mandiki SNM, Kestemont P. Are cortisol and melatonin involved in the immune modulation by the light environment in pike perch sander lucioperca? J Pineal Res 2019; 67(1):e12573 https://doi.org/10.1111/jpi.12573

[21] Magrone T, Magrone M, Jirilo E, Eosinophils. a jack of all trades in immunity: therapeutic approaches for correcting their functional disorders. Endocr Metab Immune Disord Drug Targets 2020; 20(8):1166-1181 https://doi.org/10.2174/1871530320666200309094726

[22] Wen T, Rothenberg ME. The regulatory function of eosinophils. Microbiol Spectr 2016; 4(5):1-19 https://doi.org/10.1128/microbiolspec.mchd-0020-2015

[23] Fulkerson PC, Rothenberg ME. Targeting eosinophils in allergy, inflammation, and beyond. Nat Rev Drug Discover 2013; 12(2):117-129 https://doi.org/10.1038/nrd3838

[24] Nemeth E, Rivera S, Gabayan B, Keller C, Taudorf S, Pedersen BK, Ganz T. IL-6 mediates hipoferremia of inflammation by inducing the synthesis of the iron regulatory hormone hepcidin. J Clin Invest 2004; 113(9):1271-1276 https://doi.org/10.1172/jci20945

[25] Muchowska KB, Varma SJ, Moran, J. synthesis and breakdown of universal metabolic precursors promoted by iron. Nature 2019; 569(7754):104-107 https://doi.org/10.1038/s41586-019-1151-1

[26] Mousa K, Gurung P, Adams-Huet B, Devaraj S, Jiadal I. Increased eosinophils in adipose tissue of metabolic syndrome. J Diabetes Complications 2019; 33(8):535-538 https://doi.org/10.1016/j.jdiacomp.2019.05.010

[27] Eng SS, Defelice ML. The role and immunobiology of eosinophils in the respiratory system: a comprehensive review. Clin Rev Allergy Immunol 2016; 50(2):140-158 https://doi.org/10.1007/s12016-015-8526-3

[28] Bapat SP, Liang Y, Zheng Y. Characterization of immune cells from adipose tissue. Curr Protoc Immunol 2019; 126(1):e86 https://doi.org/10.1002/cpim.86

[29] Smith KA. Frontiers in Immunology - Grand challenges. Frontiers in Immunology 2010; 1:1-2 https://doi.org/10.3389/fimmu.2010.00001

[30] Pedersen BK, Febbraio MA. Muscle as an endocrine organ: focus on musclederived interleukin-6. Physiol Rev 2008; 88, n. 4, p. 1379-1406 https://doi.org/10.1152/physrev.90100.2007 